\title{
OTC medicines-are they 'open to criticism'?
}

\author{
Paul Turner
}

Department of Clinical Pharmacology, St. Bartholomew's Hospital, London EC1A 7BE, UK.

There are three categories of medicine in terms of their availability to the public; (a) prescription only (POM), which can only be obtained on a medical or dental prescription; (b) pharmacy only (P), which do not require such a prescription, but can only be purchased in a pharmacy under the supervision of a registered pharmacist; and (c) medicines on the General Sales List, which are available, usually in restricted quantities, through other non-pharmacy retail outlets. In the United Kingdom only the first and third of these categories are legally defined. Any drug or preparation which is not included within them falls into the pharmacy-only list. ${ }^{1}$ Medicines available in the second and third categories are often referred to as 'over-thecounter' or OTC medicines.

A major determinant of the status of a medicine is its safety record, determined by its therapeutic ratio, and in countries with vigilant drug regulatory authorities OTC medicines generally have a reasonable safety record. $^{2}$ For example, ibuprofen, the non-steroidal anti-inflammatory analgesic drug, was a recent addition to the OTC market in the United Kingdom. Experience during 14 years of prescription-only availability had shown it to be of low toxicity both generally and in overdose. During the first 2 years following its introduction in August 1983 as an OTC analgesic there was, perhaps not surprisingly, a marked increase in enquiries to the National Poisons Information Service concerning ibuprofen overdose, but no evidence of a concurrent increase in severity of poisoning from it. ${ }^{3}$ This confirms the results of surveys conducted in the USA where ibuprofen was granted an OTC licence in $1984 .^{4}$

As might be expected, pharmacists and the pharmaceutical industry wish to see an extension of the OTC drug market by a reduction in the number available only on prescription. ${ }^{5}$ Some clinicians have also suggested that it would be appropriate to grant some more drugs OTC status. There has been controversy in the medical journals between distinguished dermatologists on whether topical hydrocortisone

Correspondence: Professor P. Turner M.D., B.S.c., F.R.C.P. Received: 3 February 1987 preparations should be sold directly to the patient under supervision of a pharmacist. ${ }^{6,7}$ It has also been suggested by a British authority on sleep that a benzodiazepine hypnotic could safely be made available over the counter in a pharmacy. ${ }^{8}$

However, while the safety record of OTC medicines in this country is not a cause for major concern, this is not true in all parts of the world, ${ }^{9}$ and vigilance is constantly required. We should proceed only cautiously towards an increase in the OTC list. Like any others which possess therapeutic efficacy, OTC medicines can produce adverse and unwanted effects, and because they are more freely available such effects may be less easily recognized. Some have marked central actions if taken in doses in excess of those recommended by the manufacturer, or even, in the case of anti-emetics such as hyoscine, in therapeutic doses. If taken without supervision by patients already receiving centrally acting drugs, dangerous summations of effects may occur. For example, Contac capsules, possessing both central nervous depressant and anticholinergic properties, can summate with other drugs possessing similar pharmacological properties such as tricyclic antidepressant drugs, to produce delirium and severe behavioural disorders. ${ }^{10}$ Drug abusers have tried to exploit the central actions of OTC medicines such as cyclizine as alternatives to less readily available drugs."

Herbal remedies are generally available without supervision, although the Medicines (Retail Sale or Supply of Herbal Remedies) Order 1977 brought the sale and supply of certain potent herbals under the control of pharmacists. Many, however, are capable of producing adverse reactions, ${ }^{12}$ and clinicians should always bear in mind the possibility that ingestion of such non-prescribed remedies might contribute to the clinical problem with which their patients present. ${ }^{13}$

Two reports of adverse effects from OTC medicines are published in this issue. ${ }^{14,15}$ Benylin is a popular and widely used expectorant even though it is no longer prescribable on National Health Service prescriptions and its use is discouraged by the British National Formulary. ${ }^{16}$ Most clinicians probably regard its major adverse effects as central nervous depression or 
dependence from its content of diphenhydramine, and this is reinforced by its accompanying "label for dispensed medicines' recommended by the British National Formulary; 'May cause drowsiness. If affected do not drive or operate machinery. Avoid alcoholic drink.' However, the case report by MacRury \& Neilson ${ }^{15}$ shows that other more subtle metabolic effects can occur in patients who take large quantities of this ammonium chloride-containing mixture over long periods of time.

Few clinicians know that kaolin and morphine mixture contains sufficient liquid liquorice extract as a flavouring agent together with sodium bicarbonate to produce unwanted effects. Hypokalaemia from excessive liquorice ingestion has been well documented, ${ }^{17}$ and this journal reported a woman who over $2-3$ years intermittently took small amounts of medicine containing equal quantities of liquorice liquid extract

\section{References}

1. Burley, D.M. \& Binns, T.B. Pharmaceutical Medicine. Arnold, London, 1985, pp 156-157.

2. Dukes, M.N.G. Patent Medicines and Autotherapy in Society. Drukkerij Pasmans, The Hague, 1963.

3. Perry, S.J., Streete, P.J. \& Volans, G.N. Ibuprofen overdose: the first two years of over-the-counter sales. Human Toxicol 1987, 6: 173-178.

4. Veltri, J.C., Rollins, D.E. \& Litovitz, T.L. Toxicological profile of ibuprofen. Veterinary and Human Toxicology 1985, 28: 312-314.

5. Pharmacy - a report to the Nuffield Foundation. The Nuffield Foundation, London, 1986.

6. Shuster, S. Over the counter sale of topical corticosteroids: the need for debate. $\mathrm{Br} M e d \mathrm{~J}$ 1985, 291: 38-39.

7. Greaves, M.W. Over the counter sale of topical corticosteroids: evidence versus anecdote. Br Med Journal 1985, 291: 276-277.

8. Oswald, I. Drugs for poor sleepers? Br Med J 1986, 292: 715.

9. Herxheimer, A. Problem drugs. World Health Forum 1983, 4: 244-247.

10. Turner, P. Clinical pharmacology in criminal cases. $J$ Roy Soc Med 1987, in press.

11. Editorial. Advice on cyclizine. Pharm J 1986, 236: 1-2.
B.P., cascara elixir B.P., and liquid paraffin, B.P., and presented with a flaccid quadruplegia due to profound hypokalaemia. ${ }^{18}$ Another paper ${ }^{19}$ reported a patient ${ }^{\circ}$ who died from extensive myocardial necrosisassociated with prolonged hypokalaemia due to abuses? of kaolin and morphine mixture. Potentially severeo adverse effects can be produced by eating large quantities of apparently harmless liquorice or pon $-\overline{\overline{\bar{N}}}$ tefract cakes, readily available from unsupervised $ه$ sources. This present case ${ }^{14}$ reminds us that the non-o therapeutic components of medicines, used for their ${ }^{\text {s }}$ flavouring or other properties, may not be inert but $\vec{\circ}$ possess important properties with unwanted effects. $\overrightarrow{\vec{H}}$ Furthermore, it illustrates that a complete drug his- $\omega$ tory should include all OTC remedies and favouriteo confectionary as part of the routine documentation of 3 patients coming under our care.

12. Anderson, L.A. \& Phillipson, J.D. Herbal medicine, education and the pharmacist. Pharm $J$ 1986, 236:C 306-308.

13. Turner, $P$. Adverse reactions to drugs in migraine; somereports. Hum Toxicol 1985, 4: 475-476.

14. Kirkham, B.W., Cowell, R.P.W. \& Rees, P.J. Severe. hypokalaemia from kaolin and morphine abuse. $P$ axtgrad Med J 1987, 63: 589-590.

15. MacRury, S. \& Neilson, R. Benylin dependence, metabolic acidosis and hyperglycaemia. Postgrad Med 1987, 63, 587-588.

16. British National Formulary, Number 11. British Medical Association, London, 1986. p129.

17. Epstein, M.T., Espiner, E.A., Donald, R.A. \& Hughes, H. Liquorice toxicity and the renin-angiotensin-aldosterone axis in man. $\mathrm{Br}$ Med J 1977, 1: 209-210.

18. Cumming, A.M.M., Boddy, K., Brown, J.J. et al. Severe hypokalaemia with paralysis induced by small doses of liquorice. Postgrad Med J 1980, 56: 526-529.

19. Barragry, J.M. \& Morris, D.V. Fatal dependence on kaolin and morphine mixture. Postgrad Med J 1980, 56: $180-181$. 